JENKINS R. (2014) BLACK MAGIC AND BOGEYMEN FEAR, RUMOUR AND POPULAR BELIEF IN THE NORTH OF IRELAND 1972-74. CORK: CORK UNIVERSITY PRESS. 306 P. ISBN 9781782050964

\author{
Oleg Oberemko \\ Associate Professor, Department of Sociology, \\ National Research University Higher School of Economics \\ Address: Myasnitskaya str., 20, Moscow, Russian Federation 101000 \\ E-mail: ooberemko@yandex.ru
}

Emeritus Professor of Sociology Richard Jenkins is known as the author of books about youth life-styles, labour markets, the hidden economy, Pierre Bourdieu, ethnicity, social identity, and other socially important topics.

The idea for his recent book was informed by local rumours circulating of black magic practitioners across the author's home region in the northern part of Northern Ireland in the second half of 1972, with initial reports of sheep being cut open, followed by a case of a murdered child occurring that remained unsolved. The book tells the story of how the local moral panic rose and fell during the half-year wave of rumours about allegedlyactual evidence of practicing witchcraft and black magic rituals, taking place in the early times of the Northern Ireland Trouble, which was the ethno-nationalist conflict ${ }^{1}$ at the end of the $20^{\text {th }}$ century between the Catholic and Protestant communities. Of course, a low intensity of background discussions about supernatural forces is usual even in spaceage everyday life, especially on the eve of such events as Halloween, but the cases when the dangers from supernatural forces become a public concern are far from usual. Thus, the story tells about a series of unusual events.

Beginning when the author was a student, the story has been being written for some 40 years to show "an example of an open-minded approach to data collection, relying on what Erving Goffman called evidence of 'mixed status': newspaper cuttings, archival material, published secondary sources of many different kinds, formal and informal interviews, and a smattering of observational field-notes" (p. xiv).

A four-decennial, thorough investigation allows for the comparison of the first-hand data of interviews and observations collected long ago with every possible documented piece of data available long after the events occurred. As a result, this raises factual issues rather than just discursive issues. Having compared the entirety of the pertinent press articles of that time with unsystematic conversations and rare academic evidence, it was strongly inferred that the moral panic had been raised not only by the journalists' lust for sensationalism: "Something was going on, something other than merely the newspapers

(C) Oleg Oberemko, 2016

(c) Centre for Fundamental Sociology, 2016

DOI: $10.17323 / 1728-192 \mathrm{X}-2016-4-220-224$

1. "Although religion has a place-and indeed an important one-in the repertoire of conflict in Northern Ireland, the majority of participants see the situation as primarily concerned with matters of politics and nationalism, not religion" (Jenkins R. [1997] Rethinking Ethnicity: Arguments and Explorations, London: SAGE, p. 120). 
printing stories" (p. 24). Despite denying the evidence of witchcrafts in the major papers, the grass-root circulation of rumours stimulated concerns of the "vulnerability of children and the risks of childhood" (p. 31), and was active and richer in details than the local press covering the topic. This in itself generated public concern.

Having the research questions of what, how, and why did it happen? shaped, the author "stepped out of the local context" to discover "helpful comparative perspectives" offered by social science: "analyses of rumour by social psychologists and sociologists, the sociological concept of 'moral panics,' modern folklorists' discussions of 'contemporary legends, and anthropological accounts of witchcraft" (p. 25, and the whole of chapter 2), and "symbolising conflicts" (p. 34-36). These referents of these concepts are theoretically ascribed with more or less definite social functions of the discontent societies: rumours "fill an information vacuum" (p. 26) in "twilight of gossip" (p. 28); moral panics "flourish in the light of day" to appoint, stigmatise and exclude the "devils" to "strengthen 'our' identity" (p. 28); contemporary (urban) legends "reduce collective anxieties which result from rapid social change" (p. 32) ${ }^{2}$; and symbolizing conflicts, here being accusations of witchcraft, are "to prevent major strife by facilitating minor conflict" (p. 35), offering "a 'safety valve' for tensions that might otherwise boil over" (p. 34-35). All of these functions could be demanded by the religious communities of Northern Ireland in 1973, since both "lived in an 'enchanted' world" (p. 36) in "a violent and risky place to live" (p. 27). In the contemporary world, all of the listed conceptions imply "complex relationships between public moral issues and private fears", and can help to equally reveal a "manipulation by elites and interest groups in the pursuit of their own agendas", or "the 'bottom up' working-through of everyday moral concerns and ambiguities" (p. 39) in the cases.

The author does not intend to annoy the reader examining all the relevant concepts since the readers can easily familiarize themselves with them. In Chapter 3, Jenkins hurries to take stock of all the evidence of the supernatural forces at play published in the press. Instead of trying to establish "whether there were practising Satanists, witches or other occultists in Northern Ireland in the early 1970s," the author attempts a more adequate task related to social science. He asks "was there any evidence in the public domain at the time that might reasonably have led people in Northern Ireland to fear Satanism, black magic and witchcraft?" (p. 53). The rather negative answer is accurate and definite. If so, it is to find "other reasons why people might reasonably have been frightened of satanic, occult forces" (p. 54).

As it follows from the findings of Chapter 4, the Satanist interpretation of the child's assassination which started the journalist discourse of the verity of black magic practices and dangers was prepared by an earlier fierce murder of two political activists, one representing the Catholic community, and the other, a Protestant. As the author infers, "in the absence of a local category of acceptable political violence which could be applied to such killings, the ferocious brutality with which [the activists] had been murdered could

2. Cit. from: Victor J. S. (1996) The Sociology of Contemporary Legends: A Review of the Use of the Concept by Sociologists. Contemporary Legend: A Folklore Bibliography, Vol. 3 (eds. G. Bennett, P. Smith), New York: Garland, p. 75. 
only be described" in terms of an "inhuman" or "diabolic" deed. In the social context of discontent and despair, a concept of "ritual killing" was ready at hand to be sounded as soon as it was possible (p. 68). The child assassination provided the opportunity.

To make such an inference, the author needed to widen the temporal and spatial framework of his investigation, and answer the question of how did the local communities prepare to accept the idea of ritual assassinations? As a plausible answer, Chapter 5 suggests the use of the British Army's "black propaganda," which had a documented experience of a related type during Kenyas War of Independence against Britain in the 1950 os (see p. 69-72). The suspicion is not the result of a pure "qualitative abduction," but has grounds in press materials of the very case. A quotation from a local paper reads that "one priest said that, in the opinion of some, such rumours [about witchcrafts and so on] were started in the North of Ireland by the powers that be for the purposes of keeping the kids off the streets at night" (p. 70). A large part of the chapter contains the analysis of an interview by the author with a former captain who "was involved at the same time [and the same region where the events the book narrates] in a psychological operations ('psy ops') unit called Information Policy, which attempted to undermine loyalist and republican paramilitary organisations by spreading disinformation about their activities" (p. 73). The captain said that, particularly during the mid-seventies, they tried to discredit the paramilitary groups "in terms of the two cultures, both republican and loyalist" (p. 76). Since the captain did not remember all the operations he had been involved in, it is inferred that his participation in the case was quite possible. Considering that the captain's services included starting rumours, organizing simulacra of black masses, and news publications among other disruptive operations, the reader gets a plausible version of the manner in which the local communities could have been prepared to accept the idea of ritual assassinations.

The next chapter shows us that no plausible reasons can substitute causal explanations. Even if a sociologist does manage to collect interviews with various protagonists of an Army "psy ops" unit with detailed descriptions of their "ops," s/he can tell rather nothing about "social facts," those actual consequences of the deeds reported in the interviews, and the consequences which had been incorporated inside the communities by the intersubjectivity. In other words, a good sociologist cannot stop his/her investigation once having revealed some traces of conspiracies by secret/military agencies. This is because naked references to secret/military agencies hide rather than explain the machinery of social interactions. To manage, secret/military agencies have to use far from secret/ military means. In propagandist uses of mass media, the quoted "authoritative experts" play their key roles; propaganda involving the occult naturally recruits moral entrepreneurs under its banner. Chapter 6 deconstructs the expertise of this kind after the same collection of the newspapers articles, though taken for a new analytical task.

Chapter 7 continues deconstructing the expertise of those journalists who wrote the articles both constructing and reporting news of the presence of the occult. To focus his studies on local journalism, the author utilizes memoirs of those journalists who had visited Northern Ireland to give a general representation of making news in the times of 
the Troubles (p. 111). This was the same collection of newspapers articles supplemented with a detailed interview of the journalist who had published a key article designed to untwist the moral panic (p. 135-140) 36 years before. The chapter finishes with a reiterative intimation, that "not everything that was rumoured found its way into print" (p. 140). That means another turn of the story, which means to have a look at the widely known tendency of the superstition of the Irish people.

Chapter 8 represents the Irish beliefs in "other world" phenomena and agents, largely in the perspective of happy childhoods when the "other world" is mostly framed with festivals and wise and powerful parents. Frightening shadows of the unknown vaguely appear only for short times. It is commonplace knowledge that the adults of the Eire are prone to superstition and the supernatural, for "Northern Ireland in $1973 \mathrm{can}$, in some senses at least, be described as an enchanted world" (p. 165). The main festival in the province under study is Halloween, which is directly connected both with "witches" and "the Devil" (p. 158). Thus, the research question for the chapter is, is it possible to discover evidence "that everyone in the north of Ireland in the early 1970 s was 'in the grip' of either a pervasive fear of witches and black magic, or were simply 'superstitious' more generally?" (p. 163). The clearly negative answer is gleaned from the analysis of the Halloween discourse of the regional newspaper, where cheerful recipes, advice, instructions, and nothing particularly anxious are to be found. However, the question arises of why did the author neglects his own maxim that "not everything that was rumoured found its way into print"? Why did not he interview any old-timers who remembered the Halloween of 1973 ?

If it was possible that no-one could remember those specific events, the author casts a spell over a dense description of the cultural context in Chapter 9 to reveal "the ways in which violence and trouble became themes in northern Irish supernatural lore" (p. 166), a new supernatural lore, which emerged by 1973 during the times of the Troubles (p. 164) with the most usual themes for any supernatural lore, those of "death, illness, uncertainty, morality, and the ambiguous status and vulnerability of children" (ibid.). The point is that many different people, whether alone, in dyads, or in triads, reported meeting the ghosts of killed or dead people. The author writes that "the increased number of ghosts since the Troubles was explained by people in Belfast during 1986 and 1987 as due to several factors: 'the sheer frequency and randomness of violent death within a limited space and time'; untimely deaths, of the young for example; and, for Catholics, deaths without benefit of the last rites" (p. 170). ${ }^{3}$ Violence generates fear, apparitions of ghosts, spirits, Bogeymen, and the sharing of rumours and stories about these encounters.

Chapter 10 focuses on the fact that "the Northern Irish black magic scare of the early 1970 s was, among other factors, shaped by local supernatural lore and organised religion". This chapter reveals the religious landscape of Northern Ireland where the Catholic majority and the Protestant minority are similar in the level of religiosity and beliefs in God's miracles, but historically dissimilar in the patterns of community life organisation, and

3. With the reference to: Feldman A. (1991) Formations of Violence: The Narrative of the Body and Political Terror in Northern Ireland, Chicago: University of Chicago Press, p. 67. 
the reactions to the rumours about the presence of the occult. Nevertheless the author argues that the moral panic would not have shown up so clearly without external influences.

As it can be seen from Chapter 11, external influences were cultural. There were mass-culture pieces and stories of black magic, witchcraft and occultism, horror fiction and cinema "from England," and especially the allegedly youth life-style patterns of sex, drugs, and so on, which were not well received in the 1970s by the rather conservative and much more religious population of Northern Ireland. The crucial point here is that "mass communications media may [might] be significant producers and transmitters of supernatural lore" in the north of Ireland during the early 1970 (p. 234).

The plot development of the book is unpredictable and keeps the reader in suspense. The eleven chapters actually represent eleven (or just a little fewer) criss-crossed perspectives of the same $3 \mathrm{D}$ picture drowning always in the same empirical data. From the point of view of the post-true rhetoric, the author might seem too neat and perhaps vanilla in his references and conclusions. This is due to the reason that the study started in 1973, and was not completed until 40 years later. As the author confesses, "whatever the study's shortcomings are, they cannot be blamed on unseemly haste" (p. xiii).

I can give at least three reasons why I would advise a reader to spend the time to read this book attentively, even if rumours, black magic, military tensions, and the Eire are far from the reader's interests. The first reason is rather ethical, since the author instructs a sociologist to refrain from hasty and facile causal explanations, even when a researcher has the moral ground to righteously declare of having spent 40 years on the research. The author differentiating between those journalists who reported the events from those who constructed them is very relevant for the actual state of the social sciences. The second reason is methodological. The book shows that a really accurate, unhurried, theoretically supported and disenchanted qualitative research can achieve its limits in finding real, factual whats, hows and whys it happened to get satisfied with a general revealing all the social forces having possibly been involved in the particular constellation in which the rest is veiled. The final reason is necessarily consolatory: as legated by C. Wright Mills, who says that the "art of bringing together public issues and private troubles" does not start "over there"; good research starts immediately.

\section{Richard Jenkins, Black Magic and Bogeymen Fear, Rumour and Popular Belief in the North of Ireland 1972-74 (Cork: Cork University Press, 2014)}

\section{Олег Оберемко}

Кандидат социологических наук, доцент департамента социологии Национального исследовательского университета «Высшая школа экономики»

Адрес: ул. Мясницкая, д. 20, г. Москва, Российская Федерация 101000

E-mail: ooberemko@yandex.ru 